\title{
Cometabolic isoterpinolene formation from isolimonene by denitrifying Alcaligenes defragrans
}

\author{
Udo Heyen, Jens Harder * \\ Abteilung Mikrobiologie, Max-Planck-Institut für marine Mikrobiologie, Celsiusstr. 1, D-28359 Bremen, Germany
}

Received 29 June 1998; received in revised form 30 September 1998; accepted 1 October 1998

\begin{abstract}
Alcaligenes defragrans strains denitrify on monoterpenes with an unsaturated hydrocarbon structure. A new cometabolic reaction, the formation of isoterpinolene from isolimonene, was detected in cultures that grew on a monoterpene. The biotransformation of isolimonene, a monocyclic monoterpene with a $s p^{3}$-hybridized $\mathrm{Cl}$ atom of the menthane skeleton, contrasts with the complete mineralization of monoterpenes with a $s p^{2}$-hybridized $\mathrm{C} 1$ atom. This selectivity indicates a demand for a $s p^{2}$-hybridized $\mathrm{C} 1$ atom as structural property for monoterpenes that can be oxidized by A. defragrans. (C) 1998 Federation of European Microbiological Societies. Published by Elsevier Science B.V. All rights reserved.
\end{abstract}

Keywords: Anaerobic degradation; Denitrification; Monoterpene; Biotransformation

\section{Introduction}

Environmental concerns have led to intensive research on anaerobic degradation of hydrocarbons, which resulted in the isolation of new bacteria capable of degrading alkanes [1,2] and aromatic compounds $[3,4]$. So far, only the biochemistry of the initial activation reaction of toluene has been revealed. A carbon-hydrogen bond of the methyl group is added to a fumarate molecule by the action of benzylsuccinate synthase, a putative glycine radical enzyme [5-7]. This unprecedented observation is of considerable interest for our understanding of en-

\footnotetext{
* Corresponding author. Tel.: +49 (421) 2028-750; Fax: +49 (421) 2028-580; E-mail: jharder@mpi-bremen.de
}

zymes [8,9] and raises the question how the mineralization of alkanes and alkenes is commenced.

Isoprene and monoterpenes are the largest natural source of alkenes. Estimated annual emission rates are in the order of $5 \times 10^{14} \mathrm{~g}_{\text {year }}{ }^{-1}$ for each class of compounds [10]. We have recently shown that monoterpenes were microbially degradable in the absence of molecular oxygen [11]. The isolation of denitrifying microbes on (+)-p-menth-1-ene, $(-)$ - $\alpha$-phellandrene, (+)-2-carene and (-)- $\alpha$-pinene yielded four strains that were described as Alcaligenes defragrans sp. nov. [12]. In this study, neutral metabolites formed during monoterpene consumption were analyzed and identified. We report the stoichiometric formation of isoterpinolene (2,4(8)-p-menthadiene, 6-methyl-3-(1-methylethylidene)-cyclohexene) from isolimonene and propose a structural requirement for the central hydrocarbon activation reaction. 


\section{Materials and methods}

A. defragrans strains $51 \mathrm{Men}, 54 \mathrm{Pin}^{\mathrm{T}}, 62 \mathrm{Car}$ and $65 \mathrm{Phen}$ and Thauera terpenica strain $58 \mathrm{Eu}^{\mathrm{T}}$ were cultivated anaerobically on monoterpene and nitrate as sole electron donor and acceptor, respectively, on a bicarbonate-buffered defined medium with a 2,2,4,4,6,8,8-heptamethylnonane (HMN) phase as described [11-13]. Typically, $30 \mu \mathrm{mol}$ monoterpene and $150 \mu \mathrm{mol}$ nitrate were present in $1.5 \mathrm{ml} \mathrm{HMN}$ phase and $15 \mathrm{ml}$ freshwater medium before inoculation. Turbidimetric determinations at $660 \mathrm{~nm}$ were performed to measure biomass formation. Samples of the aqueous and the HMN phases were withdrawn with sterile, $\mathrm{N}_{2}$-flushed plastic and glass syringes, respectively. Nitrite and nitrate were quantified by anion exchange HPLC as described [11]. Concentrations of monoterpenes relate to the aqueous phase. Monoterpenes were determined by dualcolumn capillary-column gas chromatography [14] and by gas chromatography-mass spectroscopy [11]. Compounds were identified by mass spectroscopy and retention time analysis (Kovàts indices). The commercially not available isoterpinolene was synthesized by acid-catalyzed isomerization of $\alpha$-phellandrene according to the literature [15]. A $1.5-\mathrm{ml}$ portion of $100 \mathrm{mM} \alpha$-phellandrene in HMN was mixed once with $20 \mathrm{ml}$ of $60 \%(\mathrm{w} / \mathrm{w})$ aqueous sulfuric acid and then incubated for $30 \mathrm{~min}$ at $67^{\circ} \mathrm{C}$. The reaction yielded according to $\mathrm{GC}$ analysis a mixture of $\alpha$-phellandrene $(70.6 \%), \alpha$-terpinene $(23.0 \%), \gamma$ terpinene $(3.3 \%)$ and isoterpinolene $(3.2 \%)$ and was used as isoterpinolene standard.

\section{Results and discussion}

The monoterpenes supporting denitrifying growth of $A$. defragrans strains contain a common structural motif: the methyl group-carrying carbon atom $(\mathrm{C} 1$ in the menthane skeleton nomenclature [15]) is $s p^{2}$ hybridized. For example, limonene, (-)- $\alpha$-pinene and (-)- $\beta$-pinene were utilized, but not isolimonene or (-)-trans-pinane [12]. Therefore we investigated the fate of isolimonene, a monocyclic compound with a $s p^{3}$-hybridized $\mathrm{C} 1$ atom, in cultures of $A$. defragrans strains and $T$. terpenica $58 \mathrm{Eu}^{\mathrm{T}}$, which is also capable of growing anaerobically on a limited range of unsaturated monoterpenes [13]. Isolimonene does not support microbial growth or denitrification of the strains $[12,13]$.

In cultures of $A$. defragrans strain $54 \mathrm{Pin}^{\mathrm{T}}$ on limonene and nitrate, isolimonene disappeared and a new neutral metabolite accumulated corresponding to the decline of isolimonene (Fig. 1). A comparison of the mass spectrum obtained by GC-MS (Fig. 2A) with published spectra [16] identified the metabolite as isoterpinolene. Because the differentiation from other structural isomers, e.g. terpinolene, was predominantly based on differences in the signal intensity

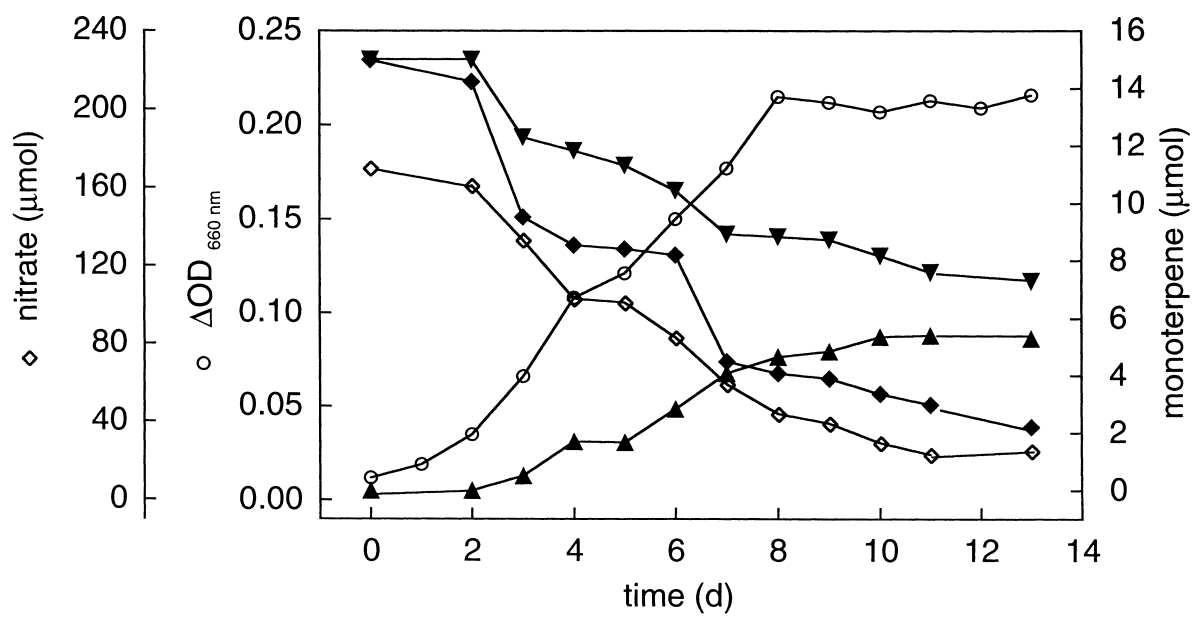

Fig. 1. Formation of a new metabolite $(\boldsymbol{\Delta})$ during growth $(\bigcirc)$ of $A$. defragrans $54 \mathrm{Pin}^{\mathrm{T}}$ on limonene $(\bullet)$, isolimonene $(\boldsymbol{\nabla})$ and nitrate $(\diamond)$. A culture tube contained $3 \mathrm{ml} \mathrm{HMN}$ and $17 \mathrm{ml}$ freshwater medium. 


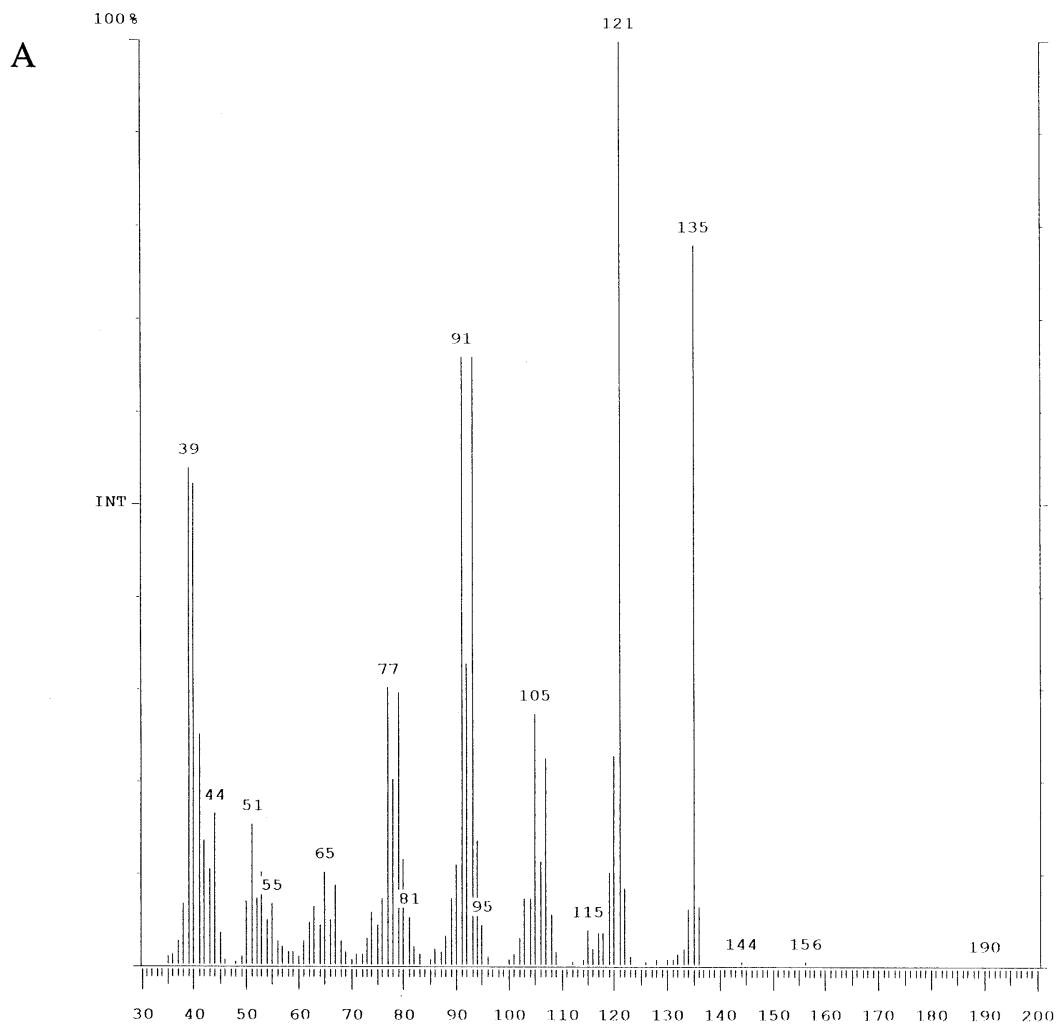

B

a

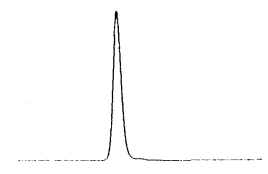

b

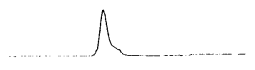

$\mathrm{C}$
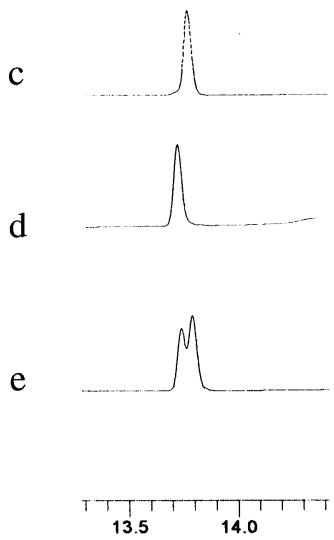

Retention time

Mass / Charge

Fig. 2. A: Mass spectrum of the new metabolite. B: GC analysis of the metabolite (trace a), isoterpinolene (b), terpinolene (c), and standard additions of the metabolite and isoterpinolene (d) and the metabolite and terpinolene (e).

of mass ions, a retention time analysis was performed and yielded a Kovàts retention index (RI) of 1091 for the metabolite. The published RI values of isoterpinolene and terpinolene, 1085 and 1088 respectively [17], were close to the determined value. Therefore an identification by coinjection with isoterpinolene or terpinolene standards was performed (Fig. 2B). The new metabolite comigrated with isoterpinolene, thus corroborating the GC-MS analysis.

The microbial synthesis of isoterpinolene from isolimonene required the presence of a physiologically active culture and the presence of a monoterpene as growth substrate (Table 1). The concentration of $1 \mathrm{mM}$ of limonene in the presence of $10 \mathrm{mM}$ of nitrate represents a carbon limitation. Hence isolimonene and isoterpinolene could be oxidized when the bacteria had the required physiological traits. However, the recovery of $64-98 \%$ of the consumed isolimonene as isoterpinolene attests that these compounds are not efficiently metabolized further during an incubation time of 3 weeks. Analysis of the electron balances indicates that more electrons became available from the complete oxidation of the disappeared amount of the growth-supporting monoterpene to carbon dioxide than are required for the reduction of the consumed amounts of nitrate. Electron ratios of 1.1-1.5 resemble earlier experiments [11-14] and sustain the hypothesis that isoterpinolene is a dead-end product.

Surprisingly, the growth-supporting monoterpene was not completely consumed. A comparison of all strains indicated a toxic effect. All four $A$. defragrans strains catalyzed the allylic isomerization, but not $T$. terpenica $58 \mathrm{Eu}^{\mathrm{T}}$ isolated on eucalyptol. Microbial growth of this strain on limonene $(1 \mathrm{mM})$ was completely suppressed in the presence of isolimonene 
Table 1

Quantification of monoterpene metabolism by nitrate-reducing A. defragrans strains and T. terpenica $58 \mathrm{Eu}^{\mathrm{T}}$

\begin{tabular}{|c|c|c|c|c|c|}
\hline Strain and substrate & $\begin{array}{l}\text { Bacterial } \\
\text { growth } \\
\left(\Delta \mathrm{OD}_{660 \mathrm{~nm}}\right)\end{array}$ & $\begin{array}{l}\text { Amount of } \\
\text { nitrate consumed } \\
\text { ( } \mu \text { mol, } \\
\% \text { consumption) }\end{array}$ & $\begin{array}{l}\text { Amount of } \\
\text { growth terpene } \\
\text { consumed ( } \mu \text { mol, } \\
\% \text { consumption) }\end{array}$ & $\begin{array}{l}\text { Amount of } \\
\text { isolimonene } \\
\text { consumed ( } \mu \mathrm{mol} \text {, } \\
\% \text { consumption) }\end{array}$ & $\begin{array}{l}\text { Amount of } \\
\text { isoterpinolene } \\
\text { formed } \\
(\mu \mathrm{mol})\end{array}$ \\
\hline \multicolumn{6}{|l|}{ Alcaligenes defragrans $54 \mathrm{Pin}^{\mathrm{T}}$} \\
\hline Limonene $(2 \mathrm{mM})$ & 0.222 & $154(100)$ & $17.0(59)$ & 0.0 & 0.0 \\
\hline Isolimonene $(2 \mathrm{mM})$ & 0.017 & $15(10)$ & - & 0.2 & 0.0 \\
\hline \multicolumn{6}{|l|}{ Alcaligenes defragrans $51 \mathrm{Men}$} \\
\hline Limonene $(1 \mathrm{mM})+$ isolimonene $(1 \mathrm{mM})$ & 0.204 & $122(85)$ & $14.2(95)$ & $1.7(11)$ & 1.1 \\
\hline \multicolumn{6}{|l|}{ Alcaligenes defragrans $62 \mathrm{Car}$} \\
\hline Limonene $(1 \mathrm{mM})+$ isolimonene $(1 \mathrm{mM})$ & 0.053 & $77(51)$ & $7.8(52)$ & $1.4(9)$ & 0.9 \\
\hline \multicolumn{6}{|l|}{ Alcaligenes defragrans $65 \mathrm{Phen}$} \\
\hline Limonene $(1 \mathrm{mM})+$ isolimonene $(1 \mathrm{mM})$ & 0.019 & $26(18)$ & 0.0 & 0.0 & 0.0 \\
\hline
\end{tabular}

( $1 \mathrm{mM})$, but could be restored by the addition of $5 \mathrm{mM}$ acetate. Thus isolimonene causes a specific inhibition of the limonene degradation.

Isoterpinolene formation from isolimonene occurred with all monoterpenes tested as substrate for growth $((-)$ - $\alpha$-pinene, limonene, $(-)-\alpha$-phellandrene or a mixture of $\alpha$-terpinene and $\gamma$-terpinene), but could not be detected in cultures utilizing either glutamate $(5 \mathrm{mM})$ or gluconate $(5 \mathrm{mM})$. This difference might be caused by either the absence of monoterpene degrading enzymes in these cultures or the low solubility of monoterpenes (ca. $50 \mu \mathrm{M}$ for alkenes) that restricts the rates of turnover in comparison to the fast growth rate on a highly water-soluble substrate.

Besides isolimonene, further monoterpenes with a $s p^{3}$-hybridized $\mathrm{C} 1$ atom were tested to identify stoichiometric biotransformations. A. defragrans strains $54 \mathrm{Pin}^{\mathrm{T}}$ and 65Phen grow on $(+)$-2-carene and on $(+)-3$-carene [12]. cis-4-Carene and trans-4-carene could not serve as growth substrate and were not cometabolically transformed during growth on 2-carene. Myrcene was utilized by $A$. defragrans 65Phen, whereas (-)- $\beta$-citronellene was neither transformed nor mineralized. A delocalized $\pi$-system is present in $p$-cymene. This compound was not attacked as sole carbon source [12] or cometabolically during growth on $(-)-\alpha$-phellandrene.
In enrichment cultures, trace amounts of microbially formed monoterpenes were noticed [11]. Similar observations were now made with pure cultures of $A$. defragrans. Neutral monoterpenes accumulated to concentrations of up to $30 \mu \mathrm{M}$ during growth on different monoterpenes. GC-MS analyses of HMN phases identified verbenene, 2,3-bis(methylene)-bicyclo[3.2.1]octane, 3-carene, eucalyptol, limonene, $\beta$ phellandrene, $\alpha$-terpinene, $\gamma$-terpinene, $\quad p$-cymene and terpinolene. These substances may be perceived either as fortuitously formed dead-end metabolites ( $p$-cymene) or as intermediates of the degradation pathway (menthadienes).
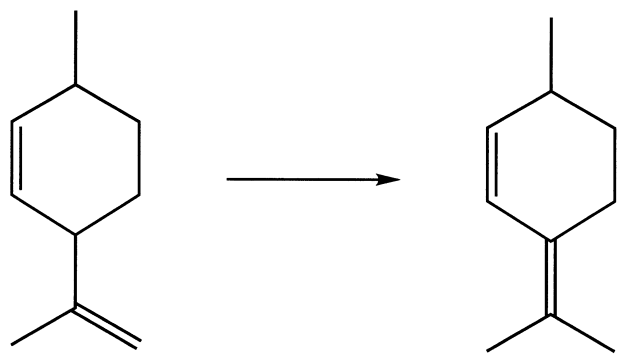

\section{isolimonene}

\section{isoterpinolene}

Fig. 3. Biotransformation of isolimonene to isoterpinolene. 
In summary, the accumulation of isoterpinolene as the product of an allylic rearrangement of isolimonene (Fig. 3) manifests the capacity of $A$. defragrans to activate alkene bonds of unsaturated monoterpenes and the necessity of a $s p^{2}$-hybridized $\mathrm{C} 1$ atom with localized bonds for the further metabolism in which the monoterpene may be transformed into an ionic compound that stays intracellular as substrate.

\section{Acknowledgments}

We like to thank Sabine Foß for critical discussions. This work was supported by the Deutsche Forschungsgemeinschaft (to J.H.) and the MaxPlanck-Gesellschaft.

\section{References}

[1] Aeckersberg, F., Bak, F. and Widdel, F. (1991) Anaerobic oxidation of saturated hydrocarbons to $\mathrm{CO}_{2}$ by a new type of sulfate-reducing bacterium. Arch. Microbiol. 156, 5-14.

[2] Rueter, P., Rabus, R., Wilkes, H., Aeckersberg, F., Rainey, F.A., Jannasch, H. and Widdel, F. (1994) Anaerobic oxidation of hydrocarbons in crude oil by new types of sulfatereducing bacteria. Nature 372, 455-458.

[3] Dolfing, J., Zeyer, J., Binder-Eicher, P. and Schwarzenbach, R.P. (1990) Isolation and characterization of a bacterium that mineralizes toluene in the absence of molecular oxygen. Arch. Microbiol. 154, 336-341.

[4] Lovley, D.R., Baedecker, M.J., Lonergan, D.J., Cozarelli, I.M., Phillips, E.J.P. and Siegel, D.I. (1989) Oxidation of aromatic contaminants coupled to microbial iron reduction. Nature 339, 297-299.

[5] Biegert, T., Fuchs, G. and Heider, J. (1996) Evidence that anaerobic oxidation of toluene in the denitrifying bacterium Thauera aromatica is initiated by formation of benzylsuccinate from toluene and fumarate. Eur. J. Biochem. 238, 661-668.
[6] Coschigano, P.W., Wehrman, T.S. and Young, L.Y. (1998) Identification and analysis of genes involved in anaerobic toluene metabolism by strain T1: putative role of a glycine free radical. Appl. Environ. Microbiol. 64, 1650-1656.

[7] Leuthner, B., Leutwein, C., Schulz, H., Hörth, P., Haehnel, W., Schlitz, E., Schägger, H. and Heider, J. (1998) Biochemical and genetic characterization of benzylsuccinate synthase from Thauera aromatica: a new glycyl radical enzyme catalysing the first step in anaerobic toluene metabolism. Mol. Microbiol. 28, 615-628.

[8] Harwood, C.S. and Gibson, J. (1997) Shedding light on anaerobic benzene ring degradation: a process unique to prokaryotes? J. Bacteriol. 179, 301-309.

[9] Heider, J. and Fuchs, G. (1997) Anaerobic metabolism of aromatic compounds. Eur. J. Biochem. 243, 577-596.

[10] Zimmermann, P.R., Chatfield, R.B., Fishman, J., Crutzen, P.J. and Hanst, P.L. (1978) Estimates of the production of $\mathrm{CO}$ and $\mathrm{H}_{2}$ from the oxidation of hydrocarbon emissions from vegetation. Geophys. Res. Lett. 5, 679-682.

[11] Harder, J. and Probian, C. (1995) Microbial degradation of monoterpenes in the absence of molecular oxygen. Appl. Environ. Microbiol. 61, 3804-3808.

[12] Foß, S., Heyen, U. and Harder, J. (1998) Alcaligenes defragrans sp. nov., description of four strains isolated on alkenoic monoterpenes $((+)$-menthene, $\alpha$-pinene, 2 - carene and $\alpha$-phellandrene) and nitrate. Syst. Appl. Microbiol. 21, 237-244.

[13] Foß, S. and Harder, J.(1998) Thauera linaloolentis sp. nov. and Thauera terpenica sp. nov., isolated on oxygen-containing monoterpenes (linalool, menthol and eucalyptol) and nitrate. Syst. Appl. Microbiol. (in press).

[14] Foß, S. and Harder, J. (1997) Microbial transformation of a tertiary allylalcohol: regioselective isomerisation of linalool to geraniol without nerol formation. FEMS Microbiol. Lett. 149, 71-75.

[15] Erman, W.F. (1985) Chemistry of the Monoterpenes. Marcel Dekker, New York.

[16] McLafferty, F.W. and Stauffer, D.B. (1989) The Wiley/NBS Registry of Mass Spectral Data. Wiley and Sons, New York.

[17] Bestmann, H.J., Kobold, U. and Vostrowsky, O. (1985) Gasphasen-Dehydratisierung von $p$-Menthenolen durch Reaktionsgaschromatographie. Korrelation der Eliminierungsprodukte mit Bildungsenthalpien aus Kraftfeldberechnungen. Liebigs Ann. Chem. 1986, 234-241. 